\title{
molecules
}

ISSN 1420-3049

www.mdpi.com/journal/molecules

Article

\section{Response Surface Methodology Optimization of Fermentation Conditions for Rapid and Efficient Accumulation of Macrolactin A by Marine Bacillus amyloliquefaciens ESB-2}

Shan He ${ }^{1}$, Hongqiang Wang ${ }^{1}$, Bin Wu ${ }^{2}$, Hui Zhou ${ }^{1}$, Peng Zhu ${ }^{1}$, Rui Yang ${ }^{1}$ and Xiaojun Yan ${ }^{1, *}$

1 Key Laboratory of Applied Marine Biotechnology, Ningbo University, Ministry of Education, Ningbo 315211, China; E-Mails: heshan@nbu.edu.cn (S.H.); whq.8685136@163.com (H.W.); zhouhui925@yeah.net (H.Z.); zhupeng@nbu.edu.cn (P.Z.); yangrui@nbu.edu.cn (R.Y.)

2 Department of Ocean Science and Engineering, Zhejiang University, Hangzhou 310058, China; E-Mail: wubin@zju.edu.cn

* Author to whom correspondence should be addressed; E-Mail: xiaojunyan@hotmail.com; Tel.: +86-574-8760-0458; Fax: +86-574-8760-0590.

Received: 20 November 2012; in revised form: 5 December 2012 / Accepted: 18 December 2012 / Published: 28 December 2012

\begin{abstract}
In the present work, an antibiotic-producing marine bacterium was isolated from a seawater sample collected from Yuhuan, Zhejiang, China, identified and named as Bacillus amyloliquefaciens ESB-2 on the basis of phenotypic characteristics and 16S rRNA gene sequencing. Response surface methodology was applied to optimize the fermentation conditions for rapid and efficient accumulation of macrolactin A, a pharmacologically important marine antibiotic. Eight fermentation conditions were examined for their significance on macrolactin A production using Plackett-Burman factorial design, where peptone, medium volume and temperature significantly improved production rate. Further optimization was carried out using Box-Behnken design of experiments to study the influence of process variables. The optimized fermentation condition for maximum production was peptone $14.8 \mathrm{mg} / \mathrm{mL}$, yeast extract $1 \mathrm{mg} / \mathrm{mL}, \mathrm{FePO}_{4} 0.01 \mathrm{mg} / \mathrm{mL}$, temperature $26.3{ }^{\circ} \mathrm{C}$, initial $\mathrm{pH}$ value 6.0 , medium volume $72.4 \%$, rotation speed $150 \mathrm{r} / \mathrm{min}$, inoculation $5 \%$ and fermented for 2 days. Under the optimized conditions, the concentration of macrolactin A reached $21.63 \mathrm{mg} / \mathrm{L}$, representing a 2.4-fold increase compared to the original standard condition, which was also $17 \%$ higher than previous highest report of $18.5 \mathrm{mg} / \mathrm{L}$ and three times higher in terms of daily productivity.
\end{abstract}


Keywords: macrolactin A; fermentation; Bacillus amyloliquefaciens; response surfaces methodology; marine antibiotics

\section{Introduction}

During the past one hundred years, natural products research has mainly concentrated on the terrestrial biota, and a lot of structurally unique and highly bioactive compounds were found in terrestrial microorganisms, plants and animals. However, for long-term research and development, discovering new and useful compound from terrestrial resources is becoming much more difficult [1]. Meanwhile, with the development of technology more and more scientists are shifting their attention to the oceans, which host the vast majority of biodiversity [2-4]. In recent years, numerous novel and complex compounds were isolated from marine organisms $[5,6]$.

Macrolactins are a group of 24-membered macrolides with potent antibacterial or other activities, most of which are produced as secondary metabolites by marine microorganisms [7]. A total of 19 isolated macrolactins were isolated and characterized [8-14]. Macrolactin A (Figure 1) was first isolated in 1989 by Gustafson et al. from a taxonomically undefined deep-sea marine bacterium. It displays a broad spectrum of biological activity, including potent cytotoxicity on B16-F10 murine melanoma cell and antiviral activity against Herpes simplex (types I and II) and HIV virus [7]. Of the 19 members, macrolactin A was considered the most bioactive. However, the extreme scarcity of material has precluded further pharmacological investigation of the compound. Hence, search for better stains and optimization of fermentation conditions to improve macrolactin A production is warranted.

Figure 1. The chemical structure of macrolactin A.

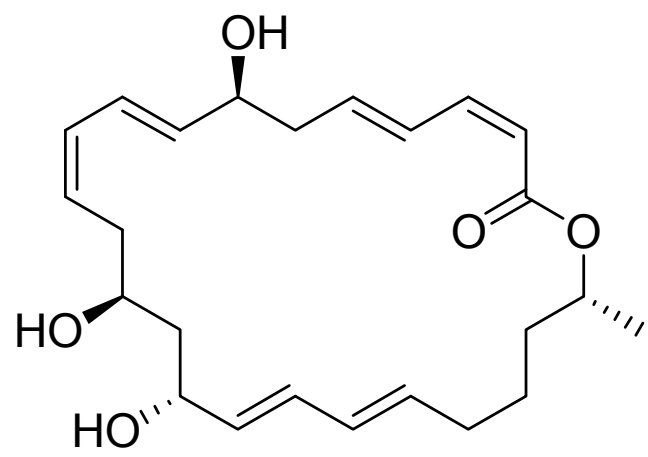

An appropriate fermentation medium is very important, because medium composition can significantly affect product yield [15]. Response Surface Methodology (RSM) is an efficient strategic experimental tool to obtain the optimum conditions for a multivariable system [16-21]. Recently, a marine bacterium was isolated from seawater in Yuhuan (Zhejiang, China) and identified and named as Bacillus amyloliquefaciens ESB-2, which was found to rapidly accumulate macrolactins. The aim of the present work was to optimize the culture medium composition for rapid and efficient production of macrolactin A by Bacillus amyloliquefaciens ESB-2 using RSM. 


\section{Results and Discussion}

\subsection{Optimization of Culture Conditions by Plackett-Burman Design (PBD)}

The importance of the eight variables, namely, peptone $\left(\mathrm{x}_{1}\right)$, yeast extract $\left(\mathrm{x}_{2}\right)$, beer extract $\left(\mathrm{x}_{3}\right)$, glucose $\left(x_{4}\right), \mathrm{FePO}_{4}\left(\mathrm{x}_{5}\right)$, medium volume $\left(\mathrm{x}_{6}\right)$, temperature $\left(\mathrm{x}_{7}\right)$ and initial $\mathrm{pH}$ value $\left(\mathrm{x}_{8}\right)$ for macrolactin A production was investigated by PBD. The effects of these components on the response and significant levels are shown in Table 1 and Table 2.

According to statistical analysis of the data by the Design Expert software Minitab 16.0 [22], peptone $\left(\mathrm{x}_{1}\right)$, medium volume $\left(\mathrm{x}_{6}\right)$ and temperature $\left(\mathrm{x}_{7}\right)$ had confidence levels above $95 \%(p<0.05)$ and were considered to influence macrolactin A production significantly. The others had confidence levels below $95 \%$ and hence were deemed insignificant. In addition, $R^{2}=0.9889$ indicated that $98.89 \%$ of the variability in the response could be explained by the model.

Table 1. The Plackett-Burman design for screening variables in macrolactin A production.

\begin{tabular}{|c|c|c|c|c|c|c|}
\hline Variable & Code & Low level (-) & High level $(+)$ & Coefficient & $t$-value & $p$-value \\
\hline Intercept & & & & 11.696 & 46.10 & 0.000 \\
\hline Peptone $(\mathrm{g} / \mathrm{L})$ & $\mathrm{x}_{1}$ & 5 & 10 & 1.328 & 5.17 & 0.014 \\
\hline Yeast extract (g/L) & $\mathrm{x}_{2}$ & 1 & 2 & -0.525 & -2.05 & 0.133 \\
\hline Beer extract $(\mathrm{g} / \mathrm{L})$ & $\mathrm{x}_{3}$ & 0 & 1 & -0.872 & -3.05 & 0.056 \\
\hline Glucose $(g / L)$ & $\mathrm{x}_{4}$ & 0 & 10 & 0.592 & 2.31 & 0.104 \\
\hline $\mathrm{FePO}_{4}(\mathrm{~g} / \mathrm{L})$ & $\mathrm{x}_{5}$ & 0.01 & 0.02 & -0.157 & -0.61 & 0.584 \\
\hline Medium volume $(\mathrm{g} / \mathrm{L})$ & $\mathrm{x}_{6}$ & $40 \%$ & $60 \%$ & 3.068 & 11.95 & 0.001 \\
\hline Temperature $\left({ }^{\circ} \mathrm{C}\right)$ & $\mathrm{x}_{7}$ & 30 & 35 & -2.272 & -8.85 & 0.003 \\
\hline Initial $\mathrm{pH}$ value & $\mathrm{x}_{8}$ & 6 & 7 & -0.148 & -0.57 & 0.606 \\
\hline
\end{tabular}

Table 2. The Plackett-Burman design along with macrolatin A production as response.

\begin{tabular}{cccccccccc}
\hline \multirow{2}{*}{ Run } & \multicolumn{10}{c}{ Variable Level } & $\begin{array}{c}\text { Macrolactin A } \\
\text { n(mg/L) }\end{array}$ \\
\hline & $\mathbf{x}_{\mathbf{1}}$ & $\mathbf{x}_{\mathbf{2}}$ & $\mathbf{x}_{\mathbf{3}}$ & $\mathbf{x}_{\mathbf{4}}$ & $\mathbf{x}_{\mathbf{5}}$ & $\mathbf{x}_{\mathbf{6}}$ & $\mathbf{x}_{\mathbf{7}}$ & $\mathbf{x}_{\mathbf{8}}$ & $\mathbf{1 7 . 8 1}$ \\
\hline 1 & -1 & -1 & -1 & 1 & 1 & 1 & -1 & 1 & 10.47 \\
2 & -1 & 1 & 1 & 1 & -1 & 1 & 1 & -1 & 7.35 \\
3 & 1 & -1 & 1 & -1 & -1 & -1 & 1 & 1 & 11.13 \\
4 & -1 & 1 & -1 & -1 & -1 & 1 & 1 & 1 & 19.29 \\
5 & 1 & -1 & 1 & 1 & -1 & 1 & -1 & -1 & 7.79 \\
6 & -1 & 1 & 1 & -1 & 1 & -1 & -1 & -1 & 16.03 \\
7 & 1 & 1 & 1 & -1 & 1 & 1 & -1 & 1 & 12.42 \\
8 & 1 & 1 & -1 & 1 & -1 & -1 & -1 & 1 & 13.87 \\
9 & 1 & -1 & -1 & -1 & 1 & 1 & 1 & -1 & 10.46 \\
10 & -1 & -1 & -1 & -1 & -1 & -1 & -1 & -1 & 4.56 \\
11 & -1 & -1 & 1 & 1 & 1 & -1 & 1 & 1 & 9.19 \\
12 & 1 & 1 & -1 & 1 & 1 & -1 & 1 & -1 & \\
\hline
\end{tabular}


PBD results also indicated that the effect of peptone $\left(\mathrm{x}_{1}\right)$ and medium volume $\left(\mathrm{x}_{6}\right)$ were positive, while temperature $\left(\mathrm{x}_{7}\right)$ exhibited a negative effect on macrolactin A production. Therefore, these three variables were selected for further optimization.

\subsection{Optimization by Response Surface Methodology}

RSM using Box-Behnken design (BBD) was employed to determine the optimal levels of the three selected variables. The respective levels with the coded levels for the factors are listed in Table 3 . The concentrations of the other factors were set at zero level as shown in Table 1. Experimental design and results are shown in Table 4.

Table 3. The level of variables for the Box-Behnken design.

\begin{tabular}{ccccc}
\hline \multirow{2}{*}{ Variables } & \multirow{2}{*}{ Code } & \multicolumn{3}{c}{ Level } \\
\cline { 3 - 5 } & & $-\mathbf{1}$ & $\mathbf{0}$ & $\mathbf{1}$ \\
\hline Peptone $(\mathrm{g} / \mathrm{L})$ & $\mathrm{x}_{1}$ & 5 & 10 & 15 \\
Medium volume $(\mathrm{mL})$ & $\mathrm{x}_{6}$ & $40 \%$ & $60 \%$ & $80 \%$ \\
Temperature $\left({ }^{\circ} \mathrm{C}\right)$ & $\mathrm{x}_{7}$ & 25 & 30 & 35 \\
\hline
\end{tabular}

Table 4. Box-Behnken design along with macrolatin A production as response.

\begin{tabular}{ccccc}
\hline \multirow{2}{*}{ Run } & \multicolumn{3}{c}{ Variable Level } & Macrolactin A \\
\cline { 2 - 4 } & $\mathbf{x}_{\mathbf{1}}$ & $\mathbf{x}_{\mathbf{6}}$ & $\mathbf{x}_{\mathbf{7}}$ & $(\mathbf{m g} / \mathbf{L})$ \\
\hline 1 & 0 & 0 & 0 & 19.08 \\
2 & 0 & -1 & 1 & 6.35 \\
3 & 0 & 1 & 1 & 6.69 \\
4 & -1 & 1 & 0 & 11.70 \\
5 & 1 & 0 & 1 & 12.56 \\
6 & 0 & -1 & -1 & 6.70 \\
7 & 1 & 0 & -1 & 20.42 \\
8 & -1 & -1 & 0 & 9.17 \\
9 & 1 & -1 & 0 & 8.40 \\
10 & -1 & 0 & 1 & 7.83 \\
11 & 0 & 0 & 0 & 19.19 \\
12 & -1 & 0 & -1 & 14.57 \\
13 & 1 & 1 & 0 & 18.21 \\
14 & 0 & 0 & 0 & 19.66 \\
15 & 0 & 1 & -1 & 19.26 \\
\hline
\end{tabular}

The relationships between macrolactin A production $(Y)$ and the tested variables were obtained by application of RSM. By employing multiple regression analysis on the experimental data, the response variable $(Y)$ and the tested variables can be related by the following second-order polynomial equation:

$$
\begin{gathered}
Y=19.31+2.04 * \mathrm{x}_{1}+3.155 * \mathrm{x}_{6}-3.44 * \mathrm{x}-1.6725 * \mathrm{x}_{1} * \mathrm{x}_{1}-5.7675 * \mathrm{x}_{6} * \mathrm{x}_{6}-3.7925 * \mathrm{x}_{7} * \mathrm{x}_{7}+ \\
1.82 * \mathrm{x}_{1} * \mathrm{x}_{6}-3.055^{*} \mathrm{x}_{6} * \mathrm{x}_{7}
\end{gathered}
$$

where $Y$ was the predicted macrolactin A production, $\mathrm{x}_{1}$ was peptone, $\mathrm{x}_{6}$ was medium volume, and $\mathrm{x}_{7}$ was temperature. 
The analysis of variance (ANOVA) data for the selected quadratic polynomial model is listed in Table 5. The high model $F$-value $(67.52)$ and low $p$-value $(<0.05)$ implied the model was highly significant. The fitness of the model could be examined by the coefficient of determination $\mathrm{R}^{2}$ [23], which was calculated to be 0.9918 , indicating that $99.18 \%$ of the sample variation was attributed to the variables and only less than $1 \%$ of the total variance could not be explained by the model. A regression model, having an $\mathrm{R}^{2}$-value higher than 0.9 , was considered as having a very high correlation. Therefore, the present $\mathrm{R}^{2}$-value reflected a very good fit between the observed and predicted responses, and implied that the model is reliable for macrolactin A production in the present study. The adjusted determination coefficient $\left(\mathrm{R}_{\text {adj }}^{2}=97.72 \%\right)$ was also able to confirm the significance of the model.

Table 5. Analysis of variance (ANOVA) for the second-order polynomial model.

\begin{tabular}{cccccc}
\hline Source & SS & DF & MS & $\boldsymbol{F}$-value & $\boldsymbol{p}$-value \\
\hline Model & 426.621 & 9 & 47.402 & 67.52 & 0.000 \\
Residual & 3.510 & 5 & 0.702 & & \\
Lack of Fit & 3.320 & 3 & 1.107 & 11.66 & 0.080 \\
Pure Error & 0.190 & 2 & 0.095 & & \\
Cor Total & 430.131 & 14 & & & \\
\hline \multicolumn{5}{c}{$\mathrm{R}^{2}=99.18 \% ; \mathrm{R}_{\text {adj }}^{2}=97.72 \%}$.
\end{tabular}

The coefficient estimates of model equation, along with the corresponding $p$-values, are presented in Table 6. The $p$-value was employed as a tool to check the significance of each coefficient, which also indicated the interactions between the variables [24]. The smaller the $p$-value, the more significant the corresponding coefficient was. It was observed from Table 6 that all regression coefficients were highly significant with $p$-values less than 0.05 except for the cross-product coefficient of peptone $\left(\mathrm{x}_{1}\right)$ and temperature $\left(\mathrm{x}_{7}\right)$.

Table 6. Regression results of the Box-Behnken design.

\begin{tabular}{ccccc}
\hline Variables & $\begin{array}{c}\text { Parameter } \\
\text { estimate }\end{array}$ & $\begin{array}{c}\text { Standard } \\
\text { error }\end{array}$ & $\boldsymbol{t}$-value & $\boldsymbol{p}$-value \\
\hline Intercept & 19.3100 & 0.4837 & 39.919 & 0.000 \\
$\mathrm{x}_{1}$ & 2.0400 & 0.2962 & 6.887 & 0.001 \\
$\mathrm{x}_{6}$ & 3.1550 & 0.2962 & 10.651 & 0.000 \\
$\mathrm{x}_{7}$ & -3.4400 & 0.2962 & -11.613 & 0.000 \\
$\mathrm{x}_{1}{ }^{*} \mathrm{x}_{1}$ & -1.6725 & 0.4360 & -3.836 & 0.012 \\
$\mathrm{x}_{6}{ }^{*} \mathrm{x}_{6}$ & -5.7675 & 0.4360 & -13.227 & 0.000 \\
$\mathrm{x}_{7}{ }^{*} \mathrm{x}_{7}$ & -3.7925 & 0.4360 & -8.698 & 0.000 \\
$\mathrm{x}_{1}{ }^{*} \mathrm{x}_{6}$ & 1.8200 & 0.4189 & 4.334 & 0.007 \\
$\mathrm{x}_{1}{ }^{*} \mathrm{x}_{7}$ & -0.2800 & 0.4189 & -0.668 & 0.534 \\
$\mathrm{x}_{6}{ }^{*} \mathrm{x}_{7}$ & -3.0550 & 0.4189 & -7.292 & 0.001 \\
\hline & & & &
\end{tabular}

The 3D response surfaces and 2D contour plots (Figures 2 and 3) generated by Minitab 16.0 are the graphical representations of the regression equation. They can visualize the relationship between the response and each variable, and the interactions between two tested variables. The $3 \mathrm{D}$ response surfaces and their respective $2 \mathrm{D}$ contours can also locate the optimum ranges of the variables for the 
maximum of the response. The maximum predicted response was indicated by the surface confined in the smallest ellipse in the contour diagram. An elliptical contour would be obtained when there was an obvious interaction between two independent variables [25].

Figure 2. $3 \mathrm{D}$ response surfaces $(\mathrm{A})$ and $2 \mathrm{D}$ contour plots $(\mathrm{B})$ showing the effects of peptone $\left(\mathrm{x}_{1}\right)$, medium volume $\left(\mathrm{x}_{6}\right)$, and their mutual interaction on macrolactin $\mathrm{A}(\mathrm{MA})$ production, when temperature $\left(\mathrm{x}_{7}\right)$ was maintained at $30^{\circ} \mathrm{C}$.

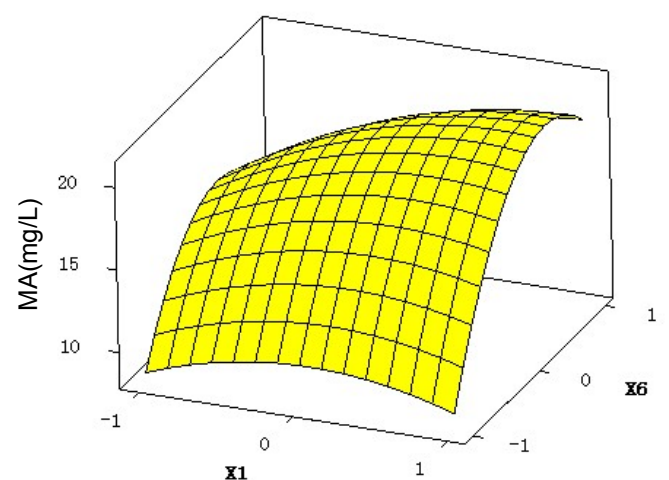

(A)

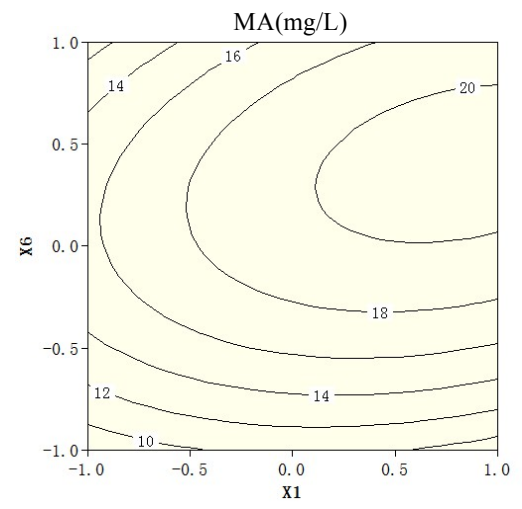

(B)

Figure 3. $3 \mathrm{D}$ response surfaces (C) and $2 \mathrm{D}$ contour plots (D) showing the effects of medium volume $\left(\mathrm{x}_{6}\right)$, temperature $\left(\mathrm{x}_{7}\right)$, and their mutual interaction on macrolactin A (MA) production, when peptone $\left(\mathrm{x}_{1}\right)$ concentration was at $10 \mathrm{~g} / \mathrm{L}$.

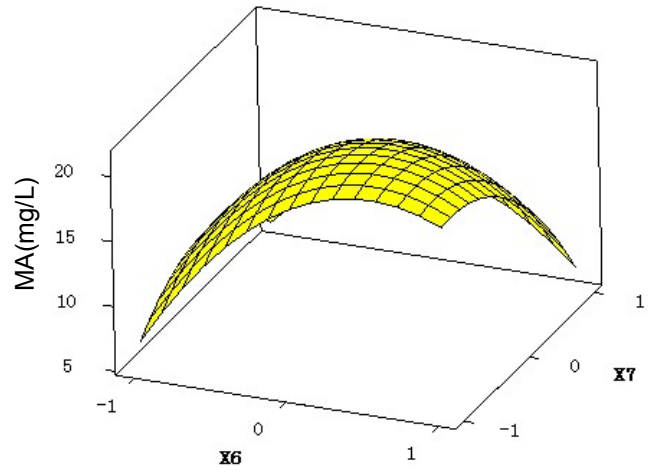

(C)

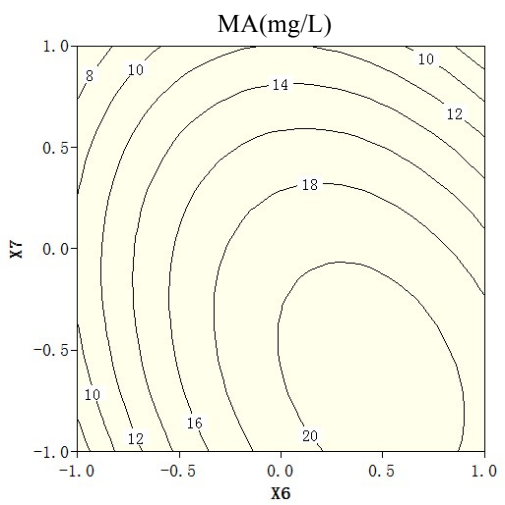

(D)

\subsection{Validation of the Optimized Condition}

On the basis of medium optimization, the quadratic model predicted that the maximum production of macrolactin A was $22.42 \mathrm{mg} / \mathrm{L}$, when the $\mathrm{x}_{1}$ code level was $0.95, \mathrm{x}_{6}$ code level was 0.62 and that of $\mathrm{x}_{7}$ was -0.74 , which were peptone $14.8 \mathrm{mg} / \mathrm{L}$, medium volume $72.4 \%$, temperature $26.3{ }^{\circ} \mathrm{C}$, respectively. To verify the predicted results, validation experiments were performed in triplicate. Under the optimized condition, the observed experimental average concentration of macrolactin A was $21.63 \mathrm{mg} / \mathrm{L}$, suggesting that experimental and predicted values $(22.42 \mathrm{mg} / \mathrm{L})$ were in good agreement, which was also $17 \%$ higher than previous highest report of $18.5 \mathrm{mg} / \mathrm{L}$ [26]. Since ESB-2 could rapidly accumulate macrolactin $A$ in only 2 days, while previous reports required more than 5 days, our result is at least three times higher in terms of daily productivity than previous reports. It is worth noting that 
the increase of macrolactin A production resulted in the decrease of other macrolactins especially macrolactin B, a glucoside of macrolactin A. The results revealed that glycosylation of macrolactin A was inhibited under the optimized fermentation condition.

\section{Experimental}

\subsection{Microorganism}

A macrolactins-producing marine bacterium was isolated from a seawater sample collected in Yuhuan, Zhejiang, China. The 16S rRNA gene sequencing result showed that this strain had 97\% homology with Bacillus amyloliquefaciens reported in the Genbank (No. JX966407). According to its morphological and physicochemical characteristics, the strain was identified and named as Bacillus amyloliquefaciens ESB-2 [27,28].

\subsection{Culture Conditions}

The bacterium was grown in $2216 \mathrm{E}$ medium $\left(5 \mathrm{~g} / \mathrm{L}\right.$ peptone, $1 \mathrm{~g} / \mathrm{L}$ yeast extract, $0.1 \mathrm{~g} / \mathrm{L} \mathrm{FePO}_{4}, 1 \mathrm{~L}$ seawater). Fermentation was performed in two stages: seed growth and macrolactin A production. For the seed growth stage, mycelium from a plate culture was inoculated into $100 \mathrm{~mL}$ of seed medium with shaking at $150 \mathrm{rpm}$ at $30{ }^{\circ} \mathrm{C}$ for $24 \mathrm{~h}$. Then, $5 \%(\mathrm{v} / \mathrm{v})$ seed cultures were inoculated into the fermentation medium. The strain was incubated at $30{ }^{\circ} \mathrm{C}$ with $150 \mathrm{rpm}$ for 2 days.

\subsection{Analytical Method}

The fermentation broth was extracted with EtOAc for three times. The extracts were evaporated and dissolved in $1 \mathrm{~mL}$ methanol. After centrifuging (12,000 rpm, $10 \mathrm{~min})$, the supernatants were analyzed by a Waters Alliance 2695 HPLC system, equipped with a quaternary solvent deliver system, an autosampler, and a 2996 diode array detector (Waters, Milford, MA, USA). A reverse-phase Waters XBridge C18 column $(150 \mathrm{~mm} \times 4.6 \mathrm{~mm}$ ID, $5 \mu \mathrm{m}$, Waters $)$ at $25{ }^{\circ} \mathrm{C}$ was applied for all analyses. Methanol-water was used as the mobile phase in gradient elution mode (methanol: 0-60 min, 10-90\%). The effluent was monitored at $280 \mathrm{~nm}$ and flow rate was $1.0 \mathrm{~mL} / \mathrm{min}$. Then authentic sample of macrolactin A with purity higher than 95\% was isolated and purified from Bacillus amyloliquefaciens by high-speed counter-current chromatography as described elsewhere [29].

\subsection{Experimental Design and Data}

Eight fermentation conditions were examined for their significance on macrolactin A production using PBD [30-32]. Further optimization was carried out using BBD experiments and RSM to study the influence of process variables on macrolactin A production [33-35].

\section{Conclusions}

This study proved that statistical experimental designs offer an efficient and feasible approach for macrolactin A fermentation medium optimization. A maximum macrolactin A production of $21.63 \mathrm{mg} / \mathrm{L}$ was achieved with the following optimized factors: peptone $14.8 \mathrm{mg} / \mathrm{mL}$, yeast extract $1 \mathrm{mg} / \mathrm{mL}$, 
$\mathrm{FePO}_{4} 0.01 \mathrm{mg} / \mathrm{mL}$, temperature $26.3{ }^{\circ} \mathrm{C}$, initial $\mathrm{pH}$ value 6.0 , medium volume $72.4 \%$ and fermented for 2 days. Under the optimized conditions, the concentration of macrolactin A reached $21.63 \mathrm{mg} / \mathrm{L}$. Validation experiments were also carried out to verify the accuracy of the model, and results showed that the predicted value agreed well with the experimental values. Comparing to $9.17 \mathrm{mg} / \mathrm{L}$ in original standard condition, 2.4-fold increase had been obtained. This medium also resulted in 17\% higher than previous report and three times higher in terms of daily productivity. The present study provides a basis for further study on large scale fermentation for macrolactin A production.

\section{Acknowledgments}

This work was financially supported by Qianjiang Talent Plan (2012R10068), National Natural Science Foundation of China (40906080, 81273386), Zhejiang Marine Biotechnology Innovation Team (2012R10029-2), Ningbo Marine Algae Biotechnology Team (2011B81007), Subject Project of Ningbo University (XKL11D2103, XKC11002), Creative Open Experiment Project of Ningbo University (Cxxkf-201226), and K.C.Wong Magna Fund in Ningbo University.

\section{References}

1. Tulp, M.; Bohlin, L. Unconventional natural sources for future drug discovery. Drug Discov. Today 2004, 9, 450-458.

2. Faulkner, D.J. Marine natural products. Nat. Prod. Rep. 2002, 19, 1-48.

3. Haefner, B. Drugs from the deep: marine natural products as drug candidates. Drug Discov. Today 2003, 8, 536-544.

4. Molinski, T.F.; Dalisay, D.S.; Lievens, S.L. Drug development from marine natural products. Nat. Rev. Drug Discov. 2009, 8, 69-85.

5. Blunt, J.W.; Copp, B.R.; Hu, W.P. Marine natural products. Nat. Prod. Rep. 2009, 26, 170-244.

6. Blunt, J.W.; Copp, B.R.; Munro, M.H.G. Marine natural products. Nat. Prod. Rep. 2010, 27, 165-237.

7. Gustafson, K.; Roman, M.; Fenical, W. The macrolactins, a novel class of antiviral and cytotoxic macrolides from a deep-sea marine bacterium. J. Am. Chem. Soc. 1989, 111, 7519-7524.

8. Jaruchoktaweechai, C.; Suwanborirux, K.; Tanasupawatt, S. New macrolactins from a marine Bacillus sp. Sc026. J. Nat. Prod. 2000, 63, 984-986.

9. Nagao, T.; Adachi, K.; Sakai, M. Novel macrolactins as antibiotic lactones from a marine bacterium. J. Antibiot. 2001, 54, 333-339.

10. Romero, T.M.; Jansen, R.; Sylla, M.; Lünsdorf, H.; Häussler, S.; Santosa, D.A.; Timmis, K.N.; Molinari, G.; Antimicrob, A.C. 7-O-malonyl macrolactin A, a new macrolactin antibiotic from Bacillus subtilis active against methicillin-resistant Staphylococcus aureus, vancomycin-resistant enterococci, and a small-colony variant of Burkholderia cepacia. Antimicrob. Agents Chemother. 2006, 50, 1701-1709.

11. Zheng, C.J.; Lee, S.; Lee, C.H.; Kim, W.G. Macrolactins O-R, glycosylated 24-membered lactones from Bacillus sp. AH159-1. J. Nat. Prod. 2007, 70, 1632-1635.

12. Xue, C.; Tian, L.; Xu, M.; Deng, Z.; Lin, W. A new 24-membered lactone and a new polyene delta-lactone from the marine bacterium Bacillusmarinus. J. Antibiot. 2008, 61, 668-674. 
13. Sohn, M.J.; Zheng, C.J.; Kim, W.G. Macrolactin S, a new antibacterial agent with FabG-inhibitory activity from Bacillus sp. AT28. J. Antibiot. 2008, 61, 687-691.

14. Mondol, M.A.; Kim, J.H.; Lee, H.S.; Lee, Y.J.; Shin, H.J. Macrolactin W, a new antibacterial macrolide from a marine Bacillus sp. Bioorg. Med. Chem. Lett. 2011, 21, 3832-3835.

15. Calam, C.T. Media for industrial fermentations. Process Biochem. 1967, 2, 19-22.

16. Baş, D.; Boyaci, I.H. Modeling and optimization I: Usability of response surface methodology. J. Food Eng. 2007, 78, 836-845.

17. Bezerra, M.A.; Santelli, R.E.; Oliveira, E.P.; Villar, L.S.; Escaleira, L.A. Response surface methodology (RSM) as a tool for optimization in analytical chemistry. Talanta 2008, 76, 965-977.

18. Gao, H.; Liu, M.; Liu, J.; Dai, H.Q.; Zhou, X.L.; Liu, X.Y.; Zhuo, Y.; Zhang, W.Q.; Zhang, L.X. Medium optimization for the production of avermectin B1a by Streptomyces avermitilis 14-12A using response surface methodology. Bioresource Technol. 2009, 100, 4012-4016.

19. Niladevi, K.N.; Sukumaran, R.K.; Jacob, N.; Anisha, G.S.; Prema, P. Optimization of lactase production from a novel strain Streptomyces psammoticus using response surface methodology. Microbiol. Res. 2009, 164, 105-113.

20. Maddox, I.S.; Richert, S.H. Use of response surface methodology for the rapid optimization of microbiological media. J. Appl. Bacteriol. 1977, 43, 197-204.

21. Cheynier, V.; Feinberg, M.; Chararas, C.; Ducauze, C. Application of Response Surface Methodology to Evaluation of Bioconversion Experimental Conditions. Appl. Environ. Microb. 1983, 45, 634-639.

22. Zhang, C.H.; Ma, Y.J.; Yang, F.X.; Liu, W.; Zhang, Y.D. Optimization of medium composition for butyric acid production by Clostridium thermobutyricum using response surface methodology. Bioresource Technol. 2009, 100, 4284-4288.

23. Pujari, V.; Chandra, T.S. Statistical optimization of medium components for enhanced riboflavin production by a UV-mutant of Eremothecium ashbyii. Process Biochem. 2000, 36, 31-37.

24. Liu, J.Z.; Weng, L.P.; Zhang, Q.L.; Xu, H.; Ji, L.N. Optimization of glucose oxidase production by Aspergillus niger in a benchtop bioreactor using response surface methodology. World J. Microb. Biot. 2003, 19, 317-323.

25. Muralidhar, R.V.; Chirumamila, R.R.; Marchant, R.; Nigam, P. A response surface approach for the comparison of lipase production by Candida cylindracea using two different carbon sources. Biochem. Eng. J. 2001, 9, 17-23.

26. Yang, Q.; Han W.J.; Zhang, W.J.; Lu X.L.; Liu, X.Y.; Xu, Q.Z.; Jiao, B.H. Identification of A Macrolactin A Antibiotic-producing Marine Bacillus amyloliquefaciens JY-863 Strain and Optimization of Its Fermentation Conditions. Pharm. Technol. 2009, 16, 311-315.

27. Garrity G.M.; Bell, J.A.; Lilburn, T.G. Taxonomic Outline of the Prokaryotes. In Bergey's Manual of Systematic Bacteriolog, 2nd ed.; Spinger-Verlag: New York, NY, USA, 2004; Volume 2, pp. 172-178.

28. Zhou, G.L.; Luo, X.S.; Tang, Y.L. Kocuria flava sp. nov. and Kocuria turfanensis sp. nov, airborne actinobacteria isolated from Xinjiang, China. Int. Syst. Evol. Microb. 2008, 58, 1304-1307. 
29. He, S.; Wang, H.; Yan, X.; Zhu, P.; Chen, J.; Yang, R. Preparative Isolation and Purification of Macrolactin Antibiotics from Marine Bacterium Bacillus amyloliquefaciens using High-Speed Counter-Current Chromatography in Stepwise Elution Mode. J. Chromatogr. A 2012, in press.

30. Plackett, R.L.; Burman, J.P. The design of optimum multifactorial experiments. Biometrika 1946, 33, 305-325.

31. Kalil, S.J.; Maugeri, F.; Rodrigues, M.I. Response surface analysis and stimulation as a tool for bioprocess design and optimization. Process Biochem. 2000, 35, 539-550.

32. Liu, G.Q.; Wang, X.L. Optimization of critical medium components using response surface methodology for biomass and extracellular polysaccharide production by Agaricus blazei. Appl. Microbiol. Biotechnol. 2007, 74, 78-83.

33. Box, G.; Behnken, D. Some New Three Level Designs for the Study of Quantitative Factors. Technometrics 1960, 2, 455-475.

34. Bingham, D. Comment on Factor Screening and Response Surface Exploration. Stat. Sin. 2001, $11,580-583$.

35. Gilmour, S. Response Surface Designs for Experiments in Bioprocessing. Biometrics 2006, 62, 323-331.

Sample Availability: Samples of the compound macrolactin A are available from the authors in case of cooperation.

(C) 2013 by the authors; licensee MDPI, Basel, Switzerland. This article is an open access article distributed under the terms and conditions of the Creative Commons Attribution license (http://creativecommons.org/licenses/by/3.0/). 